\title{
Risk of cardiovascular diseases and gastrointestinal tract disorders in relation to the impact of shift work among male workers of textile mills in Pali district of Rajasthan, India
}

\author{
R. Ranawat* and R. Srivastava \\ Department of Home Science, Jai Narain Vyas University, Jodhpur (Rajasthan), INDIA \\ *Corresponding author. E-mail: raginiranawat20@gmail.com
}

Received: November 5, 2016; Revised received: March 18, 2017; Accepted: June 30, 2017

\begin{abstract}
The present study was conducted in textile mill of Pali city with the objective to study the risk of cardiac and gastric problems in relation to shift work among male workers. The results showed significant difference between Body Mass Index $\left(x^{2}=14.2, p=0.0008\right)$ and waist hip ratio $\left(x^{2}=5.2, p=0.0226\right)$ of shift and non shift workers. Results on food intake showed comparatively more deficient daily intake of nutrients like fiber $(7.21 \mathrm{~g}), \beta$ carotene $(1842.89 \mu \mathrm{g})$, and folic acid $(99.03 \mu \mathrm{g})$ in shift workers with respect to recommended dietary allowances and an overconsumption of fats $(37.72 \mathrm{~g})$. Alcoholism $\left(x^{2}=17.3, p=0.0001\right)$ and smoking habit $\left(x^{2}=14, p=0.0029\right)$ was found to be significantly higher among shift workers. Comparatively higher segment of shift workers suffered from hypertension (56.0\%), disturbed appetite (87.50\%), stomach upsets $(90.0 \%)$, nausea $(88.50 \%)$, heartburn $(85.0 \%)$ and breathlessness (34.0\%). Shift workers also had higher mean levels of lipid profile fractions and relatively more subjects fell into the category of high risk $(20.50 \%)$ of CVD. Longer duration of involvement in shift work also influenced the occurrence of gastric and cardiac problems like disturbed appetite $\left(x^{2}=9.96, p=0.0411\right)$, stomach upsets $\left(x^{2}=9.73, p=0.0452\right)$, stomach ache $\left(x^{2}=10.1, p=0.0389\right)$, constipation $\left(x^{2}=9.88, p=0.0424\right)$, dizziness $(47.37 \%)$, breathlessness $(50.0 \%)$ and swollen feet $(44.74 \%)$. The study concludes that shift work affects food intake, BMI, WHR, BP, alcohol intake, smoking habits and lipid profile of the subjects, thus increasing the risk of health problems like cardiovascular and gastric diseases.
\end{abstract}

Keywords: CVD, Food Intake, Gastric Problems, Lipid Profile, Shift Work

\section{INTRODUCTION}

Industrialization has been recognized as the main solution to the problem of unemployment in developing countries like India, in recent years. There has been a steady increase in the number of persons employed in various factories, over the past few years. However, data on nutritional status of factory workers are lacking and thus more attention needs to be given to obtain data on the physical and nutritional status of different categories of workers in different income groups, their knowledge and practices regarding health and nutrition. Nutritional status, health status and occupational stress are distinct but interrelated factors. Any variation in one factor will affect other two factors (Sassoon, 2010).

Textile industry touches the lives of all people in one or the other ways. In Rajasthan state particularly, textile mills represent an important economic sector. In Pali district, with highest number of textile mills in the state, the work never stops. It is a round the clock operating sector where shift work is highly prevalent. According to National Sleep Foundation (2014), a shift worker is anyone who follows a work schedule that is outside of the typical "9 to 5" business day. In the past few decades the world has become increasingly dependent upon shift workers to meet the demands of globalization and our 24-hour society. Shift work has many varied forms and does not solely include night shift as is the common belief, but encompasses afternoon and evening shifts, nights, rotating shifts, on-call work and with the inclusion of regular dayshifts (Blachowicz and Letizia, 2006).

As per International Classifications of Sleep Disorders given by American Academy of Sleep Medicine (2014) shift workers are at increased risk for a variety of chronic illnesses such as heart disease and gastrointestinal diseases. Whether this is related to the fact that shift workers are awake and active during the night hours or because they tend to get fewer hours of sleep overall than traditional workers is not known. Shift-work seriously affects the health and well-being of millions of people worldwide, and the number of shift workers is constantly rising (currently approximately $20 \%$ of the workforce) (Juda et al., 2010). There is evidence in the scientific literature of adverse physiological and psychological effects of shift work, including disruption to biological rhythm, sleep disorders, health 
problems, diminished performance at work, job dissatisfaction, and social isolation (Admiet al., 2008).

The study was conducted with the objectivesto study the food intake, prevalence of cardiovascular and gastric problems in the workers and determine the impact of shift work over the risk of these problems among the subjects.

\section{MATERIALS AND METHODS}

A sample size of total 400 textile mill male workers was selected through scattered purposive sampling technique which involves selecting members from the population to comprise a sample because they specifically meet some prescribed purpose of specific attributes of interest that address the purpose of a particular research problem under investigation. Purposive sampling is used primarily in causal-comparative (ex post facto) research where the researcher is interested in finding a possible cause-and-effect link between two variables, one of which has already occurred (Essays, 2013).Out of these 400 workers, 200 engaged in shift work and rest 200 from non-shift working category was chosen. Workers were selected using the following criteria-

Age between 20-50 years.

Minimum 2 years of work experience in shift system (for shift workers).

Free from any degenerative disease like cancer, diabetes, osteoporosis etc.

Willing to participate in the study.

A structured interview schedule was developed keeping in view of the information to be collected for the study from shift workers. Standard Shift work Index (SSI) developed by Barton et al. (1995) was used in the questionnaire to collect information regarding shift duration and type, health problems etc. The interview schedule for non shift workers was kept same as shift workers, with the only difference of omission of questions pertaining to shift work. Measurements and indices like height (Jelliffe, 1966), weight, waist circumference and hip circumference of the subjects were taken and desirable body weight, body mass index (BMI) and waist-hip ratio (WHR) were calculated. The height was measured using vertical anthropometer rod. A platform spring balance was used for measuring weight. BMI was calculated by dividing the absolute weight $(\mathrm{Kg})$ with absolute height $(\mathrm{m})$ squared. Desirable or correct body weight (DBW) of the subjects was calculated using the formula:

Desirable body weight $(\mathrm{DBW})=$ height in $\mathrm{cm}-100 \ldots$.. (1) Waist circumference was measured midway between the lower rib margin and the iliac crest. Hip circumference was measured at the point yielding maximum circumference over the buttocks. Measurements were taken by non-stretchable tape and their ratios were calculated using following formula:

WHR $=$ Waist Circumference $(\mathrm{cm}) /$ Hip Circumference (cm) .

A dietary survey was conducted using 24 hours recall method for one day. The quantity of different food items consumed by the subjects were asked and then converted in terms of their raw ingredients. The nutrient intake was calculated using nutritive value given in food composition table (Gopalanet al., 2002). The intake of nutrients was compared with the RDA suggested by Indian Council of Medical Research (2010) for adult male.

Blood pressure was estimated by using Automatic Blood Pressure Monitor (Omron HEM 7132). B.P.of the subjects was compared according to categories given by JNC VIII classification (Bell et al., 2015) of hypertension. As per "The Risk Assessment Index for Cardiovascular Disease" given by Easwaranet al. (2001), scores were given to each of the information provided by the subjects. These scores were summed up and the subjects were categorized on the basis of total scores obtained, in low, medium or high risk category. From each risk group $20 \%$ of the subjects, who were willing to cooperate, were selected for the estimation of their lipid profile.Lipid profile covers serum cholesterol, serum triglyceride and lipoproteins i.e. high density lipoprotein (HDL), low density lipoprotein (LDL) and very low density lipoprotein (VLDL). Serum cholesterol, Serum triglyceride and high density lipoprotein (HDL) were estimated by enzymatic methods, using estimation kits of ERBA diagnostic limited. Additional parameters like low density lipoprotein and very low density lipoprotein were calculated by using following standard formulas:

VLDL-C $=$ Triglyceride $/ 5$.

LDL-C $(\mathrm{mg} / \mathrm{dl})=$ Total cholesterol $-($ HDL cholesterol

+ Triglyceride/5)

The data were statistically analyzed as per the objectives of the study. t- Test and chi square tests were applied to find out the statistically significant difference between the data of shift and non-shift workers.

\section{RESULTS AND DISCUSSION}

The average duration of shift work of the subjects was 13.86 years, with the subjects working in three shifts, viz. morning, day and night shift. The morning shift timings is 6:30 AM to 3:00 PM; day shift lasts from 3:00 PM to 11:30 PM and thereafter night shift starts from 11:30 PM and ends at 6:30 AM.

The shift system in which the subjects worked was found to be of irregular type i.e. there was no roster. The subjects working in night shift for a particular time would then either be transferred to morning shift or day shift. The fixed roster of transferring night shift subjects to morning shift and then day shift was not followed. About 25.50 percent of shift working subjects wanted to give up shifts and work in a day time job whereas 37.0 percent refused to give up working in shifts as it provided them more time to work second jobs. 
Table 1. Anthropometric measurements of subjects.

\begin{tabular}{lcc}
\hline Parameters & $\begin{array}{c}\text { Non-shift } \\
\text { Workers } \\
(\mathbf{n = 2 0 0})\end{array}$ & $\begin{array}{c}\text { Shift work- } \\
\text { ers } \\
(\mathbf{n}=\mathbf{2 0 0})\end{array}$ \\
\hline Desirable body weight & & \\
(DBW): & 21.0 & 13.5 \\
Less than DBW & 15.0 & 9.0 \\
Correct weight for height & 31.0 & 39.0 \\
Up to 10\% above DBW & 25.0 & 24.0 \\
10\% above DBW & 8.0 & 14.5 \\
20\% above DBW & 0 & 0 \\
$40 \%$ above DBW & & \\
Body mass index (BMI): & & \\
$<18.5$ (Underweight) & 9.0 & 1.50 \\
18.5 - 22.9 (Normal) & 31.0 & 22.0 \\
$23-24.9$ (Overweight) & 27.0 & 36.50 \\
$25-29.9$ (Pre Obese) & 29.0 & 33.0 \\
$\geq 30$ (Obese) & 4.0 & 7.0 \\
Waist hip ratio (WHR): & & \\
$\leq 0.85$ & 31.0 & 21.0 \\
$0.86-1$ & 69.0 & 79.0 \\
$>1$ & 0 & 0 \\
\hline
\end{tabular}

Table 2. Percentage distribution of subjects with respect to alcohol intake and smoking habit.

\begin{tabular}{lcc}
\hline Food habits & $\begin{array}{c}\text { Non-shift } \\
\text { Workers } \\
(\mathbf{n = 2 0 0})\end{array}$ & $\begin{array}{c}\text { Shift workers } \\
(\mathbf{n}=\mathbf{2 0 0})\end{array}$ \\
\hline Alcoholism: & 39.0 & \\
1-2 pegs/day & 29.0 & 34.50 \\
>2 pegs/day & 32.0 & 47.50 \\
Non user & & 18.0 \\
Smoking habit: & 28.50 & 13.50 \\
1 - 5 cigarettes/bidis per day & 31.0 & 41.50 \\
5-10cigarettes/bidis per day & 26.50 & 36.0 \\
>10 cigarettes/bidis per day & 14.0 & 9.0 \\
Non smoker & & \\
\hline
\end{tabular}

According to Health and Safety Authority (2012), there are many different types of shift work, with variations in shift duration, number of shifts, shift rotation, rest periods between shifts and days off. The design of a particular shift pattern is a science in itself and will depend on many factors including business needs and the type of work being undertaken.

Anthropometric measurements of the subjects: Data in table 1 depicts that shift working subjects had higher weights, Body Mass Index and WHR than desirable levels as compared to non-shift working subjects who had more number of workers falling in normal categories of anthropometric measurements. As per the Asia Pacific classification of BMI (WHO, 2000), it was found that the percentage of shift workers falling into underweight $(1.50 \%)$ and normal BMI category $(22.0 \%)$ were lower than those of non-shift workers. However, in the higher weight categories, the picture changes as the number of overweight $(36.50 \%)$ and obese $(7.0 \%)$ shift workers were higher than the non-shift workers. Hence, the chi square test statistic in
Table 3. Percentage distribution of subjects with respect to blood pressure and pulse rate.

\begin{tabular}{lcc}
\hline Parameters & $\begin{array}{c}\text { Non-shift } \\
\text { Workers } \\
(\mathbf{n}=\mathbf{2 0 0})\end{array}$ & $\begin{array}{c}\text { Shift work- } \\
\text { ers } \\
\text { (n=200) }\end{array}$ \\
\hline Blood pressure (mmHg) & & \\
$<120 / 80$ (Normal) & & 10.0 \\
120-139/80-89 (Pre Hy- & 17.0 & 34.0 \\
pertension) & 44.0 & 49.0 \\
140-159/90-99 (Stage I & 35.0 & 7.0 \\
Hypertension) & 4.0 & \\
$>139 / 89$ (Stage II Hyper- & & \\
tension) & & \\
Pulse rate (number/ & & \\
minute) & 12.0 & 6.50 \\
$<70$ & 40.50 & 26.50 \\
$70-80$ & 37.0 & 44.0 \\
$80-90$ & 10.5 & 23.0 \\
$>90$ & & \\
\hline
\end{tabular}

case of desirable body weight $(11.9, \mathrm{p}=0.0182)$, body mass index (14.2 $\mathrm{p}=0.0008)$ and waist hip ratio (5.2, $\mathrm{p}=0.0226$ ) was found to be statistically significant based on $\alpha$ level of significance (0.05). Based on these results it was observed that shift work influenced the weight, BMI and WHR of the subjects. There can be many contributory factors like lack of exercise, higher intakes of tea and fried food items available during odd working hours, disrupted schedules etc. which can explain the higher weights in shift workers than nonshift workers. These results are in line with the findings of Devadarshini et al. (2011) in which higher difference was noticed in mean weight of the shift workers $(73.67+9.92 \mathrm{~kg})$ in comparison to the day workers $(67.52+8.32 \mathrm{~kg})$, which was statistically significant. The mean BMI of the shift workers was $25.82 \mathrm{~kg} / \mathrm{m} 2$ which was higher than that of day workers, $23.37 \mathrm{~kg} /$ $\mathrm{m} 2$ and this difference was statistically significant. Suwazonoet al. (2008) also reported a significantly increased risk of $\geq 5 \%$ weight gain among shift compared to daytime workers. Tada et al. (2014) found that during rotating shift work, shorter sleep and more consumption of sugar sweetened beverages was observed, as a result there was an increase in BMI among shift workers.

Nutrient intake: As depicted in Fig. 1, it is clear that difference between the nutrient intakes among the groups, though low, the intakes of all major nutrients were higher in shift workers than day workers, with exceptions of fiber and $\beta$ carotene. The results further indicated that diet of all the subjects was improper and deficient in one or more nutrients. The situation is most alarming in the intakes of fiber, $\beta$ carotene and folic acid where it isn't even half of the recommended levels. On the other hand, intake of fat exceeded the RDA in both groups, with shift working subjects' intake being as high as 150.88 percent of RDA. It can be attributed to the higher waking hours of shift workers which resulted in higher consumption of fried foods 
Table 4. Lipid profile of selected subjects.

\begin{tabular}{lcc}
\multicolumn{1}{c}{ Lipid Profile } & $\begin{array}{c}\text { Non-Shift Workers } \\
(\text { Mean } \pm \text { SE) }\end{array}$ & $\begin{array}{c}\text { Shift Workers } \\
\text { (Mean } \pm \text { SE) }\end{array}$ \\
\hline Total-C $(\mathrm{mg} / \mathrm{dl})$ & $178.52 \pm 15.23^{*}$ & $187.12 \pm 17.67$ \\
Triglycerides $(\mathrm{mg} / \mathrm{dl})$ & $134.31 \pm 10.08$ & $139.21 \pm 8.65$ \\
HDL-C $(\mathrm{mg} / \mathrm{dl})$ & $44.20 \pm 2.13^{*}$ & $40.47 \pm 1.88$ \\
LDL-C $(\mathrm{mg} / \mathrm{dl})$ & $108.53 \pm 7.73^{*}$ & $115.21 \pm 6.59$ \\
VLDL-C $(\mathrm{mg} / \mathrm{dl})$ & $24.68 \pm 2.15$ & $26.35 \pm 2.83$ \\
\hline
\end{tabular}

$*=$ significant at $5 \%$ level of significance

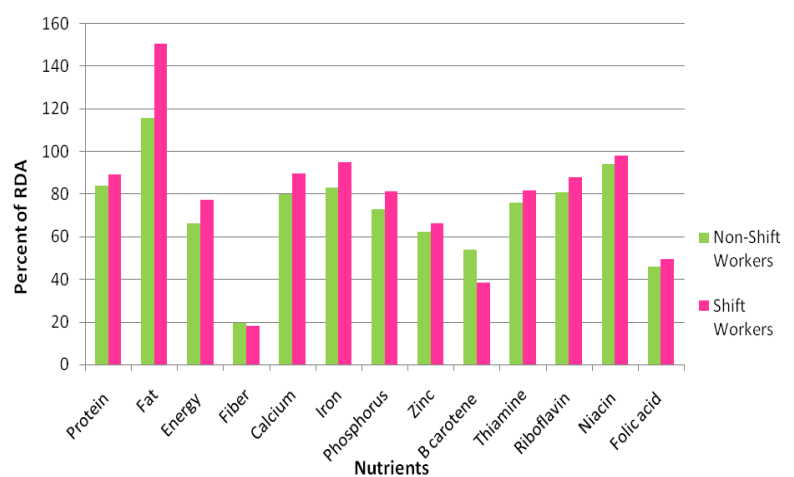

Fig. 1. Nutrient intake of subjects in relation to RDA.

and tea. According to Atkinsonet al. (2008), meal frequency is generally reduced but snacking is increased on the night shift. Unavailability of preferred foods in the workplace, a lack of time, and a reduced desire to eat at night explain these findings. 'Normal' eating habits with the family are also disrupted. The metabolic responses to food are also altered by shift work-mediated disruptions to sleep and circadian rhythms.

Bilici and NavruzVarli (2016) studied the nutritional status of nurses in turkey and found that the mean daily energy intake was higher for shift workers (1756 \pm 659 $\mathrm{kcal})$ than for day workers $(1694 \pm 431 \mathrm{kcal})(\mathrm{p}>0.05)$. Shift workers' carbohydrate intake $(196.3 \pm 85.5 \mathrm{~g}$ and $185.9 \pm 54.7 . \mathrm{g}$, respectively) and fat intake (respectively $79.5 \pm 29.5 \mathrm{~g}$ and $77.1 \pm 22.6 \mathrm{~g})$ were higher while protein intake ( $57.6 \pm 21.6 \mathrm{~g}$ and $59.4 \pm 17.6 \mathrm{~g}$, respectively) was lower than those of day workers. Except for the mean daily intake of calcium and sodium, the intakes

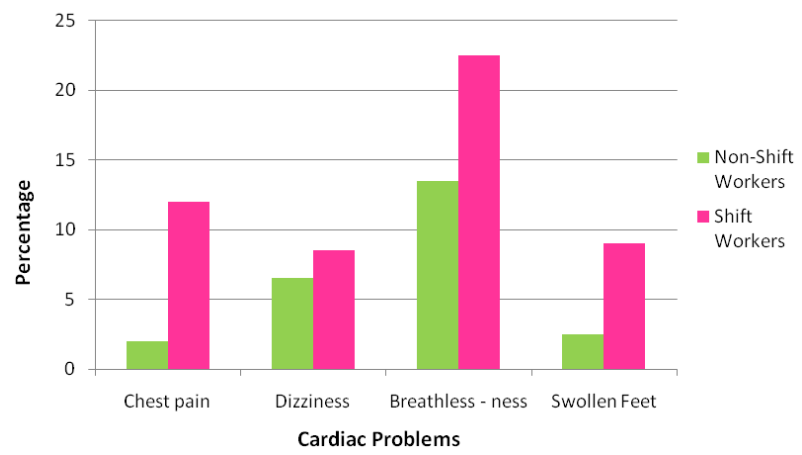

Fig. 3. Percentage distribution of subjects facing cardiac problems on regular basis.

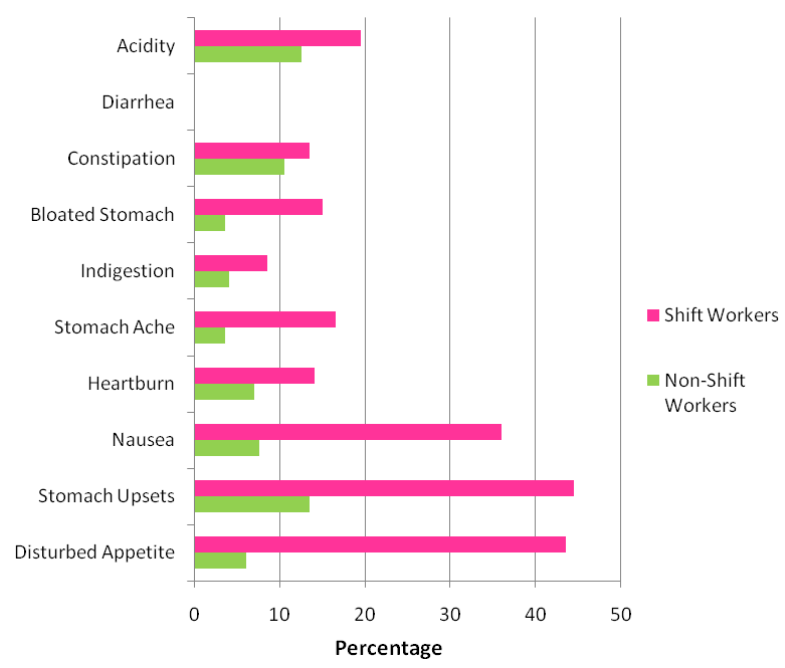

Fig. 2. Percentage distribution of subjects facing gastric problems on regular basis.

of all minerals were higher in day workers than in shift workers.

Alcohol intake and smoking habit: Habit of alcohol intake (table 2) was found to be higher in shift workers as nearly 47.50 percent subjects consumed more than two pegs per day as compared to 29.0 percent in day workers. Non users of alcohol were considerably higher in non-shift workers $(32.0 \%)$ than shift workers (18.0\%). Like alcohol, smoking habit was also higher in shift working subjects with 41.50 percent subjects smoking five to ten bidis/cigarettes per day, followed by 36.0 percent smoking more than ten bidis/ cigarettes per day. Non-shift working subjects had

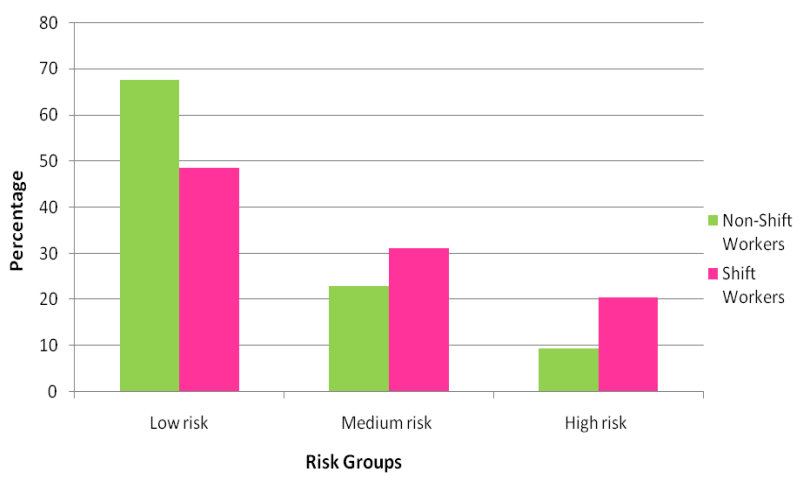

Fig. 4. Percent distribution of subjects in different risk groups. 


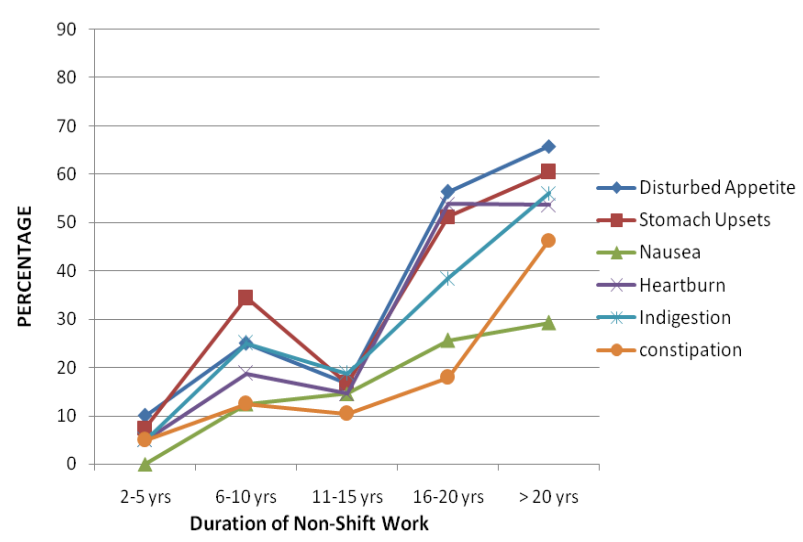

Fig. 5. Percentage distribution of subjects with respect to duration of non-shift work and gastric problems.

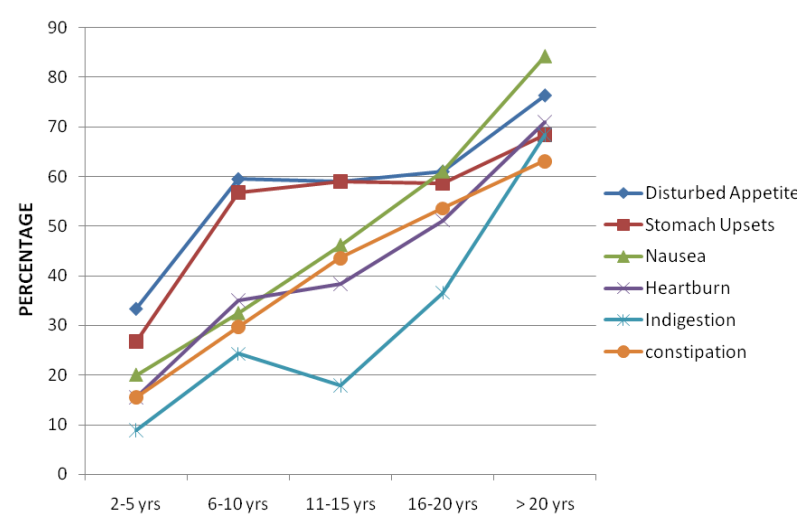

Fig. 6. Percentage distribution of subjects with respect to duration of shift work and gastric problems.

comparatively lower smoking percentages. The chi square test statistic in case of alcoholism $\left(\chi^{2}=17.3\right.$, $\mathrm{p}=0.0001)$ and smoking habit $\left(\chi^{2}=14.0, \mathrm{p}=0.0029\right)$ was found to be statistically significant based on $\alpha$ level of significance (0.05). Ramin et al. (2015) reported that among modifiable risk factors like BMI, higher daily caloric and caffeine intake and shorter sleep duration, night shift workers were also more likely to be smokers (7\% vs. 5\%) as compared to day workers. Wirth et al. (2014) had the findings in same line and reported higher prevalence of smoking habit, tobacco intake and unhealthy dietary practices. In a study by Asare-Anane et al. (2015) on cocoa processing company workers, it was found that 33.63 percent shift workers consumed alcohol as compared to 27.59 percent of non-shift workers. Puttonen (2010) also associated shift work with tobacco smoking, alcohol consumption and unhealthy dietary patterns. The systematic review by Frost et al. (2009) was based on 14 studies, of which six reported on smoking and found that it was generally more frequent among shift workers.

Blood pressure and pulse rate: Data pertaining to blood pressure (table 3 ) revealed that according to JNC VIII classification (Bell et al., 2015) majority of the subjects in non-shift working category $(44.0 \%)$ had pre

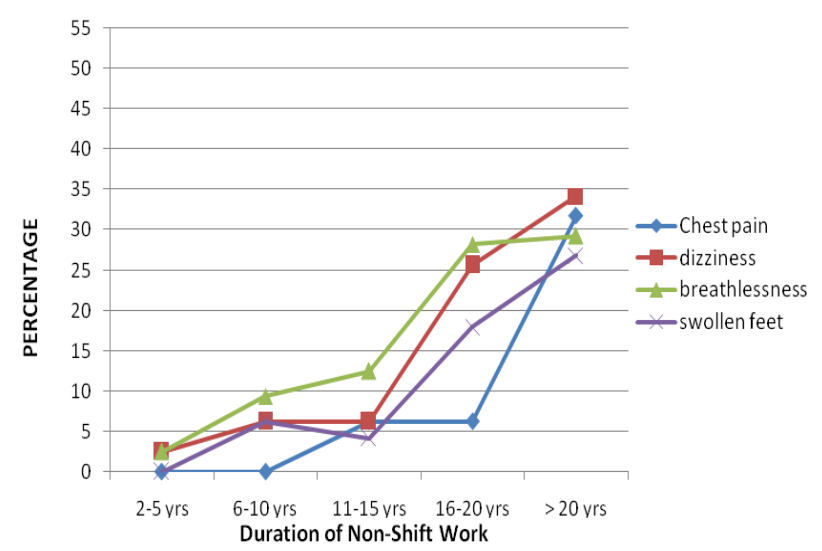

Fig. 7. Percentage distribution of subjects with respect to duration of non-shift work and cardiac problems.

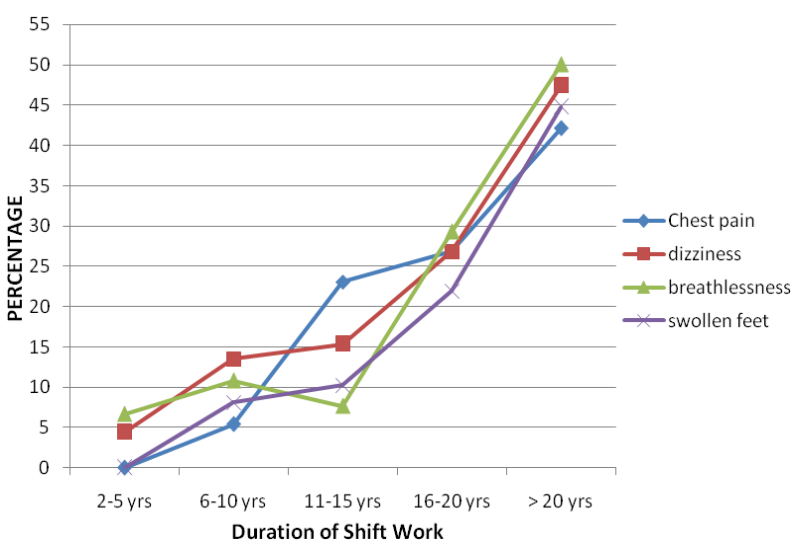

Fig. 8. Percentage distribution of subjects with respect to duration of shift work and cardiac problems.

hypertension with systolic blood pressure ranging from 120-139 $\mathrm{mmHg}$ and diastolic blood pressure ranging from $80-89 \mathrm{mmHg}$, whereas majority of the shift workers $(49.0 \%)$ were stage I hypertensive as they had blood pressure between 140-159/90-99 mmHg. Only 10.0 percent of shift workers had normal blood pressure $(<120 / 80 \mathrm{mmHg})$ as compared to the 17.0 percent of non-shift workers. Stage II hypertension was found in 7.0 percent of shift workers as compared to 4.0 percent of day workers. The chi square test statistic in case of blood pressure $(12.1, p=0.0023)$ was found to be statistically significant based on $\alpha$ level of significance (0.05) whereas no significant difference was found in case of pulse rate. Based on these results it was observed that shift work influenced the blood pressure of the subjects. Similar outcomes were found in a study by Kwatra and Singh (2012) which was carried out to assess the physiological and psychological cost of work. The result revealed significant difference in physiological parameters i.e. blood pressure, heart rate and psychological parameters of the respondents denoting their stress and fatigue due to shift work.

Gastrointestinal problems: The major problems regarding GIT (Fig. 2) faced by the subjects on a regular basis were disturbed appetite and stomach 
upsets, which were found to be more prevalent among shift workers $(43.50 \%$ and $44.50 \%)$ than non-shift workers $(6.0 \%$ and $13.50 \%)$. Nausea and heartburn along with indigestion and constipation were sometimes faced by a large number of subjects, especially in shift workers $(52.50 \%, 71.0 \%, 53.0 \%$ and $64.50 \%)$ than non-shift working group (13.0\%, $60.50 \%, 53.0 \%$ and $28.0 \%$ ). The gastric problems least experienced were stomach ache, bloated stomach and diarrhea. The chi square statistic in case of regular occurrence (31.8) of gastric problems among the subjects was found to be statistically significant ( $p=0.0002$ ) based on $\alpha$ level of significance (0.05).A recent systematic review by Knutsson and Boggild (2010) of twenty peer reviewed epidemiological studies, reporting an association between shift work and gastrointestinal diseases, pointed out that four out of six studies showed a statistically significant association with digestive symptoms, five out of six with peptic ulcers, and two out of three with functional GI disorders.

Shift work has been implicated by Zimberg et al. (2012) with multiple health problems over the long term. Specifically there is a greater chance for developing nutritional and metabolic disorders like altered metabolism, insulin resistance, diabetes, obesity, peptic ulcers, dyslipidemias, metabolic syndrome and gastrointestinal disorders. Evidence has shown that over a 4 to 5-year period, in both male and female shift workers the risk of the development of metabolic syndrome is more than day time workers. As per Koradecka (2010), disorders of normal digestive system functions and metabolism, such as diarrhea, constipation or heartburn, may occur frequently in night shift workers compared to day workers. They result from improper nutrition, in terms of both the food quality and the time of meal consumption. Irregular meal times interfere with the production of hormones, acids and enzymes necessary for food digestion, a diurnal function. Like other body rhythms, the digestive process slowly and only partly can become accustomed to an atypical activity- sleep pattern.

Cardiac problems: Breathlessness was found to be most prevalent on a regular basis (Fig. 3) among nearly a quarter of the shift working subjects $(22.50 \%)$.Apart from this, dizziness was also more faced by shift workers sometimes $(28.0 \%)$. Chest pain and swollen feet were least experienced cardiac problems for both groups. Fig. 3 also depicts that the cardiac problems are more prevalent among the shift workers than non-shift workers. The chi square statistic in case of regular occurrence of cardiac problems (7.92) among the subjects was found to be statistically significant ( $p=0.0477$ ) based on $\alpha$ level of significance (0.05).

In a study on Finnish middle-aged men by Wang et al. (2015), weekend shift work appeared to accelerate the formation of carotid atherosclerosis, at an even greater speed among men with preexisting CVD. Circadian disruption caused by shift work has been shown to affect a number of risk factors for developing CVD including blood pressure and blood lipids (De Backer, 2009). A number of studies have shown that shift work is associated with coronary heart disease (CHD) (Vyas et al., 2012), but the evidence on a causal relationship is limited. CHD and ischemic stroke have many common risk factors (O'Donnell et al., 2010), that to some extent have been associated with shift work.

Categorization of the subjects on the basis of risk factors: Fig. 4 shows that although majority of the subjects in both groups fell into low risk of CVD category, there was a marked difference in the distribution of shift and non-shift working subjects in the three risk groups. Comparatively more number of non-shift work subjects $(67.50 \%)$ fell into low risk category than shift workers $(48.50 \%)$, whereas in medium risk group, shift workers $(31.0 \%)$ were higher than day workers $(23.0 \%)$. High risk category had shift work subjects $(20.50 \%)$ that were more than twice the number of non-shift work subjects $(9.50 \%)$ in the same category. The chi square statistic in case of risk groups (16.6) was found to be statistically significant $(p=0.0002)$ based on $\alpha$ level of significance $(0.05)$. It proves that the distribution of subjects among high, medium and low risk categories was different and got influenced by shift work.

The study by Abbaszadeh et al. (2014) aimed to determine the prevalence of disorders associated with shift work among security staff in a refinery complex. The prevalence of health problems among the shift workers was greater than day workers. Meanwhile, there were significant differences between shift and day workers in terms of gastrointestinal distress $(p=0.034)$ cardiovascular disease $(p=0.028)$, hypertension $(p=0.021)$, and the feeling of fatigue $(p=0.004)$. The results of this study indicated that shift working could be associated with physical complications such as gastrointestinal diseases, cardiovascular diseases, and disturbances in circadian rhythm.

Lipid profile of selected subjects: Data in table 4 shows significant difference in total cholesterol, High Density Lipoprotein (HDL $\square$ C) and Low Density Lipoprotein (LDL-C) levels of shift and non-shift workers. Mean levels of all lipid profile fractions were found to be higher in shift working subject except HDL-C which was found to be lower. As per ATP III classification (National Heart, Lung and Blood Institute, 2001), the mean total cholesterol levels in both the groups were found to be in desirable category $(<200 \mathrm{mg} / \mathrm{dl})$. Normal levels were recorded in case of mean triglycerides $(<150 \mathrm{mg} / \mathrm{dl})$ and HDL-C $(40-60 \mathrm{mg} / \mathrm{dl})$ in both the groups, however the mean HDL-C level of shift workers $(40.47 \mathrm{mg} / \mathrm{dl})$ was extremely close to the low category $(<40 \mathrm{mg} / \mathrm{dl})$. The mean levels of LDL-C were found to be falling in 
above optimal category (100-129 mg/dl) in both the groups. The data reveals a comparatively higher risk of cardiovascular diseases for shift workers than those who are non-shift workers based on lipid profile levels. These results were in line with a cross-sectional study on shift and non-shift workers from an industry in Ghana by Asare-Anane et al. (2015), which found that the mean values for lipid profile fractions (all in $\mathrm{mmol} /$ L) like total cholesterol $(5.9 \pm 1.3$ vs. $5.2 \pm 1.7, \mathrm{p}=$ $0.002)$; triglycerides $(1.3 \pm 0.8$ vs. $1.1 \pm 0.6, \mathrm{p}=0.015)$ and LDL cholesterol $(3.6 \pm 0.9$ vs. $3.2 \pm 1.3, \mathrm{p}=0.04)$ and very low density lipoproteins (VLDL) $(0.6 \pm 0.4$ vs. $0.5 \pm 0.3, p=0.014)$ were significantly higher among the shift workers as compared to non-shift workers.

Other studies assessing lipids in shift workers have had variable results. In a follow-up study by Morikawa et al. (2007), the increases in total cholesterol were similar among day and shift workers. On the contrary, a methodologically similar 14-year follow-up study found a higher increase in total cholesterol among Japanese shift workers (Dochi et al., 2009). In an Italian male cohort with repeated health examinations, night workers had significantly higher total cholesterol than their daytime colleagues (Biggi et al., 2008).

Duration of shift work and gastric problems: There are two trends depicted in Fig. 5 and 6. Firstly, it shows consistent increase in the percentage of shift workers suffering from various gastric problems and secondly, the percentage of subjects suffering from these problems even during the initial years of work is vastly different in shift and non-shift workers. Like in case of disturbed appetite, the percentage of non-shift subjects working for more than twenty years and suffering from this problem were 55.85 percent higher than those working for only two to five years, whereas, in case of shift workers, this difference was found to be only 43.0 percent.

Another notable thing which pertains to the second trend is that in subject group working for only two to five years in non-shift work; merely 10.0 percent were suffering from disturbed appetite, whereas the subject group involved in shift work for just two to five years had as high as 33.33 percent with disturbed appetite. These trends were followed in problems like stomach upsets, nausea, heartburn, indigestion and constipation where shift workers not only had higher percentages suffering from majority of these problems as compared to those in non-shift working group, but also the subjects involved in shift work for barely two to five years and suffering from gastric problems mentioned above were far higher than subjects occupied in non-shift work for the same period. The most serious of these problems were found to be nausea, heartburn, indigestion and constipation.

The chi square test statistic in case of disturbed appetite (9.96, $\mathrm{p}=0.0411)$, stomach upsets (9.73, $\mathrm{p}=0.0452)$, stomach ache $(10.1, \mathrm{p}=0.0389)$ and constipation $(9.88$, $\mathrm{p}=0.0424$ ) was found to be statistically significant based on $\alpha$ level of significance (0.05). Based on these results it was observed that duration of shift work influenced the occurrence of gastric problems among the subjects.

Duration of shift work and cardiac problems: The problems like dizziness $(47.37 \%)$, breathlessness $(50.0 \%)$ and swollen feet $(44.74 \%)$ were found to be much higher among the subjects involved in shift work (Fig. 8) for more than twenty years as compared to subjects occupied in non-shift work (Fig. 7) for the same duration. However, non-shift workers had higher prevalence of chest pain $(36.58 \%)$ among subjects working for longest periods as compared to shift workers $(31.57 \%)$

Another trend worth noting is that problems like dizziness and breathlessness had comparatively early onsets in shift workers (by 2 to 5 years) and affected large number of subjects when compared to non-shift workers who had late onsets and lower number of subjects suffering from these problems. As per Tucker et al.(2012) participants who had been working on rotating shifts for more than 10 years were found to be more likely to exhibit symptoms of metabolic syndrome than participants with no exposure to any form of shift work, even after controlling for age and gender. According to Vetter et al. (2016), compared with women without a history of rotating night shift work, women who worked less than 5 years of shift work at baseline did not have a significantly increased CHD risk in age-adjusted analyses, but there was a significant association between longer durations of shift work and CHD risk. Longer time since quitting shift work was associated with decreased CHD risk among ever shift workers in the Nurses' Health Survey 2 ( $\mathrm{P}<.001$ for trend).

In another study, the authors reported an association between lifetime exposure to shift work and unfavorable changes in autonomic cardiac control related to a decrease in parasympathetic modulation, indicating a higher level of cardiac stress. The same study also reported an association between lifetime exposure to shift work and increased blood pressure (Souza et al. 2015). There are other studies that also support an association between shift work and high blood pressure, for example (Ohlander et al. 2015), while other studies do not (Gholami-Fesharaki et al. 2014)

\section{Conclusion}

The present study revealed that majority of the shift workers were smokers, consumed alcohol, had deficient diet and were suffering from sleep related problems. The preference of fried and fatty foods over vegetables and fruits was also highly common amongst the shift working subjects. Furthermore, comparatively higher percentage of subjects involved in shift work 
was found to be at high and medium risk of cardiovascular diseases. High consumption of fatty foods, unhealthy habits like alcohol consumption and smoking contributed to the risk of CVD and GIT disorders among the subjects. The duration of shift work also depicted an adverse impact over the risk factors and led to early onsets of cardiac and gastric symptoms, the occurrence of which got more regularized with continuous involvement in shift work. Nutritional programs focusing on industrial workers should be organized so as to make them aware about the impact of shift work and the possible lifestyle modifications like regular exercise, low saturated fat intake, high fiber intake etc. to prevent the occurrence of CVD and GIT disorders.

\section{REFERENCES}

Abbaszadeh, M., Jalali, M., Krozdeh, J., Mardi, H., Panjali, H. and Zakerian, S. A. (2014).Shift work and its complications: A case study in the security personnel of a refinery complex. Journal of Ergonomics, 2(1):46-53

Admi, H., Tzischinsy, O., Epstein, R., Herer, P., \& Laue, P. (2008). Shift work in nursing: Is it really a risk factor for nurses' health and patient's safety? Nursing Economics, 26(4):250-257.

American Academy of Sleep Medicine (2014). International classification of Sleep Disorders. American Academy of Sleep Medicine, 3rd edn, Darien, IL.

Asare-Anane, H., Abdul-Latif, A., Ofori, E.K., AbdulRahman, A., Amanquah, S.D. (2015). Shift work and the risk of cardiovascular disease among workers in cocoa processing company, Tema. BMC Research Notes, 8: 798 .

Atkinson, G., Fullick, S., Grindey, C. and Maclaren, D. (2008). Exercise, energy balance and the shift workers. Sports Medicine, 38(8):671-85

Barton, J., Costa, G., Smith, L., Spelten, E., Totterdell, P. and Folkard, S. (1995). The Standard Shiftwork Index: A battery of questionnaires for assessing shiftworkrelated problems. Work \& Stress, 9:3-30.

Bell, K., Twiggs, J. and Olin, B.R. (2015). Hypertension: The Silent Killer: Updated JNC-8 Guideline Recommendations. Continuing Education. Alabama Pharmacy Association. Retrieved From:

https://c.ymcdn.com/sites/aparx.siteym.com/resource/resmgr/ CEs/CE_Hypertension_The_Silent_Killer.pdfon 13th October 2016

Biggi N, Consonni D, Galluzzo V, Sogliani M, Costa G. (2008). Metabolic syndrome in permanent night workers. Chronobiol Int., 25:443-54

Bilici, S. and NavruzVarli, S. (2016). The nutritional status of nurses working shifts: A pilot study in Turkey. Rev. Nutr., 29 (4).

Blachowicz, E. and Letizia, M. (2006). The challenges of shift work. Medsurg. Nursing, 15 (5): 274-280.

De Backer, G., De Bacquer, D., Braeckman, L., Clays, E., Kittel, F. and Van Risseghem, M. (2009). Rotating shift work and the metabolic syndrome: a prospective study. Int. J.Epidemiol, 38:848-854

Devadarshini, C., Kasturiba, B. and Yenagi, N. (2011). Nutritional Status of Shift Workers. Karnataka J. Agric. Sci., 24 (4): 612-615.
Dochi, M., Suwazono, Y., Sakata, K., Okubo, Y., Oishi, M. and Tanaka K. (2009). Shift work is a risk factor for increased total cholesterol level: a 14-year prospective cohort study in 6886 male workers. Occup. Environ. Med., 66:592-7

Easwaran, P., Remya, R. and Uma, N.S. (2001). Formulation of "Risk Assessment Index" to predict Cardiovascular Disease among young adults. The Indian J. Nutr. Dietet., 38:1 $\square 10$

Essays, U. K. (November 2013). Sampling Methods and Techniques. Retrieved from:https://www.ukessays.com/ essays/business/sampling-methods-and-techniques.php? cref $=1$ on 13th February 2017.

Frost, P., Kolstad, H.A. and Bonde, J.P. (2009). Shift work and the risk of ischemic heart disease - a systematic review of the epidemiologic evidence. Scand J. Work Environ. Health, 35(3):163-179

Gholami-Fesharaki, M., Kazemnejad, A., Zayeri, F., Rowzati, M., Sanati, J. and Akbari, H. (2014). Multicenter historical cohort study of the relationship between shift work and blood pressure. ARYA Atheroscler., 10 (6): 287-91

Gopalan, C., Ramashastri, B.V. and Balasubramaniam, S.C. Revised and updated by Rao, B.S., Deosthale, Y.G. and Pant, K.C. (2002). Nutritive value of Indian food. National Institute of Nutrition, ICMR, Hyderabad.

Health and Safety Authority (2012). Guidance for Employers and Employees on Night and Shift Work. Health and Safety Authority, The Metropolitan Building, James Joyce Street, Dublin 1: 3.Retrieved From:http:// www.hsa.ie/eng/publications_and_forms/publications/ healthcare_sector/night_and_shift_work_2012.pdf on 17th February 2017.

ICMR (2010). Nutrient requirements and recommended dietary allowances for Indians: A report of the expert group of the Indian Council of Medical Research. NIN, Hyderabad.

Jelliffe, D.B. (1966). Assessment of the nutritional status of community. WHO monograph series no. 53, Geneva.

Juda, M., Kantermann, T., Roenneberg, T. and Vetter, C. (2010). Shift-work research: Where do we stand, where should we go? Sleep and Biological Rhythms, 8 (2):95105.

Knutsson, A.and Bøggild, H. (2010). Gastrointestinal disorders among shift workers. Scand J. Work Environ Health, 36: 85-95.

Koradecka, D. (2010).Handbook of occupational safety and health. CRC Press, Boca Raton, FL 33487-2742.

Kwatra, S. and Singh, D. (2012). Psycho-physiological effects of shift work on the lives of railway employees: An ergonomic intervention. International Journal of Advanced Engineering Research and Studies, 1(2):99105.

Morikawa, Y., Nakagawa, H., Miura, K., Soyama, Y., Ishizaki, M. and Kido, T. (2007). Effect of shift work on body mass index and metabolic parameters. Scand $J$. Work Environ. Health, 33(1):45-50.

National Heart, Lung, and Blood Institute. (2001). ATP III At a glance: Quick Desk Reference. U.S. Department of Health and Human Services. Public Health Service. Retrieved From:http://www.nhlbi.nih.gov/health-pro/ guidelines/current/cholesterol-guidelines/quick-deskreference-html on 13th October 2016 
National Sleep Foundation. (2014). Shift Work and Sleep. Retrieved From:https://sleepfoundation.org/sleeptopics/shift-work-and-sleep/page/0/3 on 5th August 2015.

O'Donnell, M.J., Xavier, D., Liu, L., Zhang, H., Chin, S.L., Rao-Melacini, P., Rangarajan, S., Islam, S., Pais, P., McQueen, M.J., Mondo, C., Damasceno, A., Lopez-Jaramillo, P., Hankey, G.J., Dans, A.L., Yusoff, K., Truelsen, T., Diener, H.C., Sacco, R.L., Ryglewicz, D., Czlonkowska, A., Weimar, C., Wang, X.and Yusuf, S. (2010). Risk factors for ischaemic and intracerebral haemorrhagic stroke in 22 countries (the INTERSTROKE study): a casecontrol study.Lancet, 376 (9735): 112-23.

Ohlander, J., Keskin, M. C., Stork, J. and Radon, K. (2015). Shift work and hypertension: Prevalence and analysis of disease pathways in a German car manufacturing company. Am. J. Ind. Med., 58: 549-60.

Puttonen, S., Härmä, M. and Hublin, C. (2010). Shift work and cardiovascular disease - pathways from circadian stress to morbidity. Scand J. Work Environ. Health, 36 (2): 96-108.

Ramin, C., Devore, E., Wang, W., Pierre-Paul, J., Wegrzyn, L.R. and Schernhammer, E.S. (2015). Night shift work at specific age ranges and chronic disease risk factors. Occup. Environ. Med., 72 (2): 100-107.

Sassoon, J.R. (2010). Diabetes in the elderly and in women. www.pubmed.gov.

Souza, B.B., Monteze, N.M., de Oliveira, F.L., de Oliveira, J.M., de Freitas Nascimento, S., Marques de Nascimento Neto, R., Sales, M.L. and Souza, G.G. (2015). Lifetime shift work exposure: association with anthropometry, body composition, blood pressure, glucose and heart rate variability. Occup. Environ. Med., 72 (3): 208-15.
Suwazono, Y., Dochi, M., Sakata, K., Okubo, Y., Oishi, M., and Tanaka, K. (2008). A longitudinal study on the effect of shift work on weight gain in male Japanese workers. Obesity (Silver Spring), 16:1887-93

Tada, Y., Kawano, Y., Maeda, I., Yoshizaki, T., Sunami, A., Yokoyama, Y., Matsumoto, H., Hida, A., Komatsu, T. and Togo, F. (2014). Association of body mass index with lifestyle and rotating shift work in Japanese female nurses. Obesity (Silver Spring), 22: 2489-2493

Tucker, P., Marquié, J. C., Folkard, S., Ansiau, D. and Esquirol, Y. (2012). Shift work and metabolic syndrome.Chronobiology International, 29(5): 549-555

Vetter, C., Devore, E. E. and Wegrzyn, L.R. (2016). Association between rotating night shift work and risk of coronary heart disease among women. JAMA, 315 (16): 17261734

Vyas, M., Garg, A.X., Iansavichus, A.V., Costella, J., Donner, A., Laugsand, L. (2012). Shift work and vascular events: systematic review and meta-analysis. $B M J, 345$ : e4800.

Wang, A., Arah, O.A., Kauhanen, J. and Krause, N. (2015). Work schedules and 11-year progression of carotid atherosclerosis in middle-aged Finnish men. Am. J. Ind. Med., 58 (1): 1-13

WHO. (2000). The Asia Pacific Perspective: Redefining Obesity and its Treatment. Health Communications Australia. 17-18. Retrieved From: http:// www.wpro.who.int/nutrition/documents/docs/ Redefiningobesity.pdf on 13th October 2016

Wirth, M.D., Burch, J., Shivappa, N., Steck, S.E., Hurley, T.G., Vena, J.E. and Hébert, J.R. (2014). Dietary inflammatory index scores differ by shift work status: NHANES 2005 to 2010. J.Occup. Environ. Med., 56 (2): $145-148$

Zimberg, I.Z., Fernandes Junior, S.A., Crispim, C.A., Tufik, S. and De Mello, M.T. (2012). Metabolic impact of shift work. Work,41 (1): 4376-4383 